\title{
Development of a Child's Semiotic Activity with the Help of Psychological Tools: A Vygotsky’s Cultural-Historical Perspective
}

\author{
Jensamut Saengpun ${ }^{1}$, Maitree Inprasitha ${ }^{2}$ \\ ${ }^{1}$ Department Doctoral Program in Mathematics Education, Faculty of Education, \\ Khon Kaen University, Khon Kaen, Thailand \\ ${ }^{2}$ Center for Research in Mathematics Education, Faculty of Education, Khon Kaen University, \\ Khon Kaen, Thailand \\ Email: jensamut.saengpun@gmail.com, Inprasitha_crme@kku.ac.th
}

Received February 22 ${ }^{\text {nd }}$, 2012; revised March 20 ${ }^{\text {th }}$, 2012; accepted April 25 $5^{\text {th }}, 2012$

\begin{abstract}
This research aims to interpret Vygotsky's theory in development of a child's semiotic activity in first grade mathematics classroom taught by open approach. This study focuses on investigate how first grade students construct signs and symbols in solving addition problems with the help of psychological tools in a mathematics classroom taught by open approach. The research was carried out in one first grade mathematics classroom including 32 students aged 6 - 7 years old and an internship student who was classroom teacher. Ethnographic methods were employed for collecting and analyzing data through classroom observation with audio-video tape recordings on 17 consecutive lessons on addition, students' written works, field note taking and interviewing the classroom teacher. The result showed that the learning and instructional materials and drawing schematic diagrams and students' language use are psychological tools that play a crucial role in development of first grade students' semiotic activity in solving addition problems. Students used units blocks and base ten blocks to operate addition with two numbers by decomposing and making ten strategies. Then, students drew schematic diagrams as symbol with their words to represent how to add two numbers corresponds to the meaning and the strategies they used.
\end{abstract}

Keywords: Semiotic Activity; Psychological Tool; Cultural-Historical Perspective; Lesson Study and Open Approach

\section{Introduction}

Vygotsky's (1986, 1998) theory stipulates that the development of the child's higher mental processes depends on the presence of mediating agents in the child's interaction with the environment. Vygotsky himself primary emphasized symbolic tool-mediators appropriated by children in the context of particular sociocultural activities, the most important of which he considered to be formal education (Kinard \& Kozulin, 2008). Cultural-historical development of human kind created a wide range of higher order symbolic tools, including different signs, symbols, writing, formulae, and graphic organizes. Individual cognitive development and the progress in learning depend, according to Vygotsky (1978), on the student's mastery of symbolic mediators and their appropriation and internalization in the form of inner psychological tools. In Vygotsky's cultural historical theory cognitive development and learning are operationalized through the notion of psychological tools. Psychological tools first appear as external symbolic tools available in a given culture (Kinard \& Kozulin, 2008).

Vygotsky (1929: p. 145) described that the culture development consists in mastering method of behavior which are based on the use of signs as a means of accomplishing any particular psychological operation. In this context culture has a special meaning for Vygotsky. As van der Veer and Valsiner (1991) mentioned, Vygotsky identified culture as sign systems-writing systems, counting systems, and language. Such sign systems- the key to a cultural-historical development of human behavior are explained as psychological tools by Vygotsky. Psychological tools are artificial instruments directed toward control over human behavior and they are the products of historical development of human behavior (Vygotsky, 1930/1997). Moreover, psychological tools are differentiated from technical tools because the technical tools change the object but influence human behavior or mind (Yoshida, 2006).

Based on Vygotsky's cultural-historical perspective discussion above, psychological tools play a crucial role in human behavior and cognition by "transforming the natural human abilities and skills into higher mental functions" (Vygotsky, 1986: p. xxv). Semiotic activity (van Oers, 2000) is one of higher mental activity of inventing symbols and attributing meanings explored by the children already from an early age. van Oers (2000: p. 147) defined the term semiotic activity as "the (inter or intra)mental activity of creating meanings and signs, by reflecting on the interrelationships between (changes in) signs and (changes in) their corresponding meanings, and of adjusting signs and meanings accordingly”. Semiotic activity (van Oers, 2000) in young children is one of mediated activity focused on supporting student to get involve in mathematical activity with the help of appropriated symbolic tool as psychological tool.

The problem in teaching mathematics in classroom that is children are often introduced to mathematics as a formal disci- 
pline by drill and practice, without a proper understanding of the relationship between sign/symbol and their meanings. The children just memorized the formal mathematics sign/symbols without the help of any mediating tool or psychological tool.

Although the discussion given above is important theoretically, it is more important to interpret the theory for enlighten development of a child's semiotic activity in a school context. This research focuses investigation on how first grade students construct signs and symbols in solving addition problems with the help of psychological tools in a mathematics classroom taught by open approach. In this study, the mathematics classroom used for analyzed is the one of mathematics classroom innovated by "Lesson Study and Open Approach" (Inprasitha, 2010) in Thailand. The open approach as a teaching approach (Inprasitha, 2010) used in this research was incorporated in the process of lesson study, the core professional development process Japanese teachers use to continually improve the quality of the learning experiences they provide to their students (Yoshida, 1999). In Thailand, Lesson Study and Open Approach is becoming an innovation for Thai teacher professional development that help teacher recognize this aspects of students' mathematics learning. In this study, the researcher presents the analysis the psychological tools that help or has a crucial role in development of first graders' semiotic activity in learning how to add two numbers from Vygotsky's culturalhistorical perspective.

\section{Methodology}

The research was carried out in one first grade mathematics classroom including 32 students aged 6 - 7 years old and an internship student who was classroom teacher. The mathematics classroom was choose to be target group is the one of classroom in Ban Nam Prae school, an elementary school in Chiang Mai province, which participated in the "Project for mathematics teacher professional development innovated by lesson study and open approach in northern educational service areas" since 2009 academic year. The project was conducted by Center for research in mathematics education, Khon Kaen University and the mathematics education program, faculty of education, Chiang Mai University.

Data were collected during November-December in the second semester of 2010 school year and consist of daily videotaped recording of 17 consecutive lessons on addition in first grade mathematics classroom made by two cameras. During in each classroom teaching, one camera focused primary on interaction between teacher and student, especially in whole-class discussion. The second camera focused on students' group working. Moreover, documentation consists of 17 lesson plans on addition; students' written works; daily field notes that summarized classroom events and student ways of thinking; and audio taped interview with the teacher. The data from the video recording of each class was transcribed into protocol to be used for video analysis and discourse analysis to analyze the semiotic activity based on the cultural-historical perspective. The analysis focused on the method by which student make their own sign and symbols in solving addition problem with the help of psychological tool.

\section{Results}

From the analysis, in each lesson of the mathematics class- room taught by Open Approach as a teaching approach has 4 steps as 1) posing open-ended problem situation 2) students' self learning 3) whole discussion and comparison and 4) summary the lesson through connecting students' ideas emerged in the classroom. Three lesson $(2 / 17,4 / 17,10 / 17)$ of a series of seventeen addition lessons were choose to evidence the origin and development of semiotic activity with the help of psychological tool. In the beginning of the lesson, the teacher typically started with the presentation of the problem situation by telling a story along with the real world objects and picture in an attempt to motivate the student to learn about addition according to the meaning of addition as "altogether" and "increasing". The task for first lesson, teacher ask student to express the addition sentence and think about how to add the two number (the number of all children in play ground) in various way as followings Figure 1.

Through this lesson, then children used units block and base-ten blocks that teacher provided as thinking tool for solving the addition problem by decomposing and composing strategy. Then, they drew picture and wrote up the process illustrated their action in thinking about adding how to solve $9+$ 4 as Figure 2.

The student reflected his thinking imagining using the number blocks and drew them up as shown above. The student took out one single unit block and used arrow to transfer it to lining of 9 blocks and finally showed the product of 10 to be combined with the rest 3 blocks making the final product of 13 . The drawing was a psychological tool for developing semiotic activity showing the thinking process using the blocks, which served as the signifiers (meaning of addition) and the signified (using the block in order to make ten).

Moreover, in the lesson $4 / 17$ on the activity-Adding $8+3$ I can do it the students used the idea discussed in the previous lesson in solving addition problem $8+3$ from which the teacher

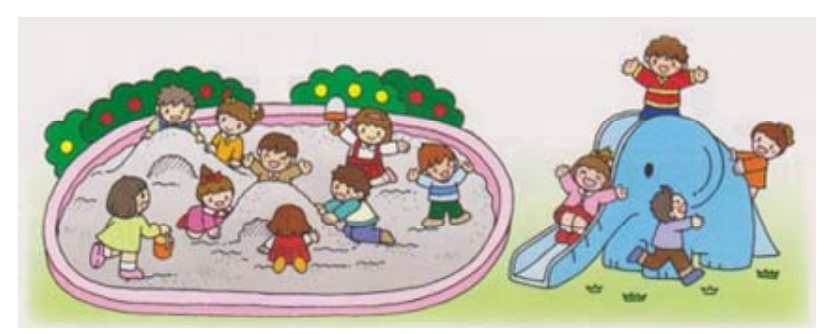

Problem: Nine students are playing with the sandbox and four ones are playing on a slide. How many students are there in all? Tasks: 1) Write mathematical sentence; 2) Show how to calculate this.

Figure 1.

Problem situation in lesson 2/17.

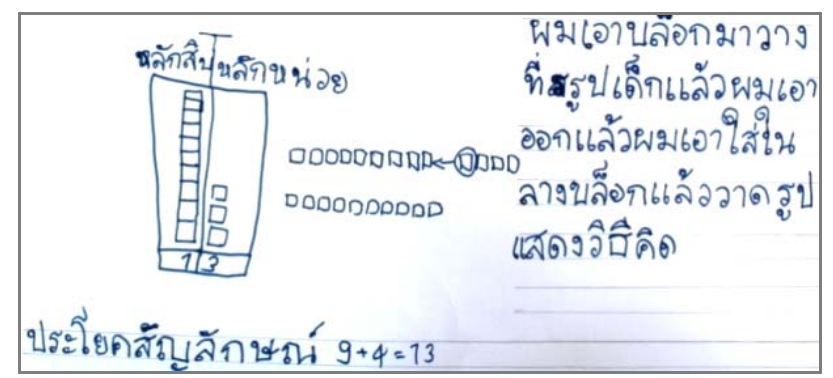

Figure 2.

Student's drawing showing using unit blocks as a tool for decomposing. 
had taken the students' idea accumulatively added up and connected it with the thinking tools such as unit blocks and base-ten block. The process further led to the development of semiotic tool such as diagram which is the psychological tool as suggested by van Oers (2000) reflected in the following protocol and the Figures 3(a), (b).

Ice: This one has only 8 , not yet full. Find 2 more to fill it up.

Teacher: I see. Class, Ice told us that there were only 8 blocks. There were none here. Two are left out. Ice then took two from there...

Ice: Yes, ...to there.

Teacher: Oh, yes. Two are placed here making it.... (Turned to other students)

Students: Ten

Teacher: Making it ten. When we put two blocks here, (wrote 2 on the two blocks). Two and 8 (drew the line between number 8 and the 2 blocks and drew the arrow down) making it...

Students: Ten

Teacher: Make it ten now (writing 10). Here, the remaining is...

Students: One

Teacher: There is only one left (writing 1 ). And now ten and one...

Ice: Combined and become 11 .

Teacher: Combined both to make... (writing + sign between 10 and 1.)

Students: Eleven (the teacher wrote equal sign followed by 11).

From above protocol, it show how the teacher led student into a semiotic activity in adjusting the sign (drawing with block) invented by children in the previous lesson to more abstract one as diagram. This process indicated that children' semiotic activity has transformed through the process of internalization from manipulative tool to inner psychological tool.

In addition, through the lesson children were able to refine the diagram by themselves. We can see that the process of creating and adjusting sign or in here the schematic diagram along with the linking of the meaning through the use of arrows and operation in each of the steps had been originated with the language interaction between the teacher and the students in discussing and comparing done together in the classroom. In the next lesson with more complex problem, we found that the students used diagramming as the tool to solve addition problems and refined the diagram to represent the variety of thinking about how to make ten from decomposing the number during the process of solving the addition problems easily and skillfully. The teacher encouraged the students to communicate their thinking with written explanation of their diagram as shown in Figure 4.

\section{Conclusion and Discussion}

Based on Vygotsky's theory, this research interprets the development of a child's semiotic activity in leaning to solve addition problem in the classroom taught by open approach as follows.

The results showed that the learning and instructional materials like unit blocks and base-ten block and drawing schematic diagrams with students' language use are psychological tools that play a crucial role in development of first grade students' semiotic activity in solving addition problems. In their development of semiotic activity in solving addition problems, stu-

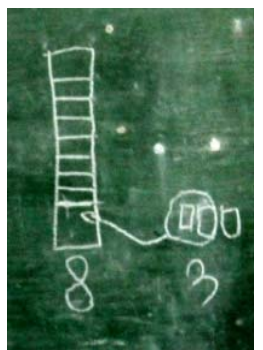

(a)

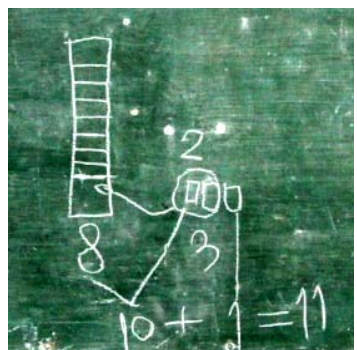

(b)
Figure 3.

Student's drawings showing thinking process on $8+3$ (a) and drawing of the teacher extending the students' thinking (b).
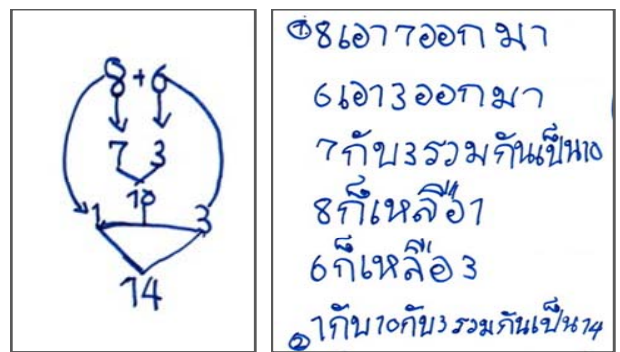

Figure 4.

Schematic diagram with their language use in explanation of solving addition problem.

dents used units blocks and base-ten blocks to operate addition with two numbers by decomposing and making ten strategies and drew iconic sign according to the action of decomposing number. Then, students drew schematic diagrams as symbol with their words to represent how to add two numbers corresponds to the meaning and the strategies they used. This finding supports van Oers (2010)'s suggestions that young children were able to reconstructed symbols according to their intentions, gradually shifting to more abstract symbolizations. From the analysis we found that, in promoting mathematical thinking like semiotic activity in young children is culturally guided process, wherein mathematical meaning can be assigned to action of the child.

From the interpretation, in conclusion, the development of a child's semiotic activity start out from the operating with manipulative materials into the children's own schematic representation and helping them to improve these representation for the use of solving more complex problems, children are personally involved in the construction of psychological tools (drawings, diagrams). Consequently, the research results confirm to van Oers (2010)'s mentions that the children learn to carry out semiotic actions with the help of these psychological tool as authenticated action of themselves. Moreover, developed semiotic activities of solving addition problem mediated by schematic diagram with the use of language helped students to learn a real concept of addition.

\section{Acknowledgements}

I would like to thank the Office of the Higher Education Commission, Thailand for supporting by grant fund under the program Strategic Scholarships for Frontier Research Network for the Ph. D. Program Thai Doctorate degree for this research. 
This work was also granted by Graduate School granting, Khon Kaen University, Thailand. Additionally, this work was supported by Center for Research in Mathematics Education, Khon Kaen University, Thailand.

\section{REFERENCES}

Inprasitha, M. (2010). One feature of adaptive lesson study in Thailand -Designing learning unit. Proceedings of the 45th Korean National Meeting of Mathematics Education, Dongkook University, Gyeongju. 193-206.

Kinard, J.T. \& Kozulin, A. (2008). Rigorous mathematical thinking: Conceptual formation in the mathematics classroom. New York: Cambridge University Press.

Kozulin, A. (1998). Psychological tools: A sociocultural approach to education. Cambridge: Harvard University Press.

Van der Veer, R. \& Valsiner, J. (1991). Understanding vygotsky: A quest for synthesis. Cambridge, MA: Blackwell.

van Oers, B. (2000). The appropriation of mathematical symbols: A psychosemiotic approach to mathematics learning. In P. Cobb, E.
Yackel, \& K. McClain (eds.), Symbolizing and communicating in mathematics classrooms (pp. 133-176). Mahwah: Erlbaum.

van Oers, B. (2010). Emergent mathematical thinking in the context of play. Educational Studies in Mathematics, 74, 23-37. doi:10.1007/s10649-009-9225-X

van Oers, B. \& Poland, M. (2007). Schematising activities as a means for young children to think abstractly. Mathematics Education Research Journal, 19, 10-22. doi:10.1007/BF03217453

Vygotsky, L.S. (1929). The problem of the cultural development of the child. The Pedagogical Seminary and Journal of genetic psychology, $36,415-434$

Vygotsky, L.S. (1978). Mind in society: The development of higher psychological processes. Cambridge: Harvard University Press.

Yohida, K. (2006). Developments of child's fraction concepts with the help of psychological tools: A Vygotsky's cultural-historical perspective. Proceedings of the 30th Conference of the International Group for the Psychology of Mathematics Education, 5, 449-456.

Yoshida, M. (1999). Lesson study: A case study of a Japanese approach to improving instruction through school-based teacher development. Ph.D. Dissertation, Chicago. IL: The University of Chicago. 